\title{
Revisiting the Effects of Blog-Aided Language Learning on EFL Student Writers: A Corpus Approach
}

\author{
Jia-Ying Lee ${ }^{1} \&$ Ming Huei Lin ${ }^{1}$ \\ ${ }^{1}$ English Department, Tamkang University, Taiwan \\ Correspondence: Ming Huei Lin, No.151, Yingzhuan Rd., Dansui Dist., New Taipei City 25137, Taiwan. E-mail: \\ johnlinminghuei@gmail.com
}

Received: March 2, 2019 Accepted: March 30, 2019 Online Published: May 8, 2019

doi:10.5539/ijel.v9n3p226 URL: https://doi.org/10.5539/ijel.v9n3p226

\begin{abstract}
Taking a corpus approach, this study analyzed writing samples collected from student bloggers and non-blogging students. The aim was to determine whether the two groups of students wrote with different linguistic features (tokens, types, token-type ratio, parts of speech, and lexical features). Any similarities and differences found in the comparison between the writing samples would have implications for the effects of the blogging approach on student writers. The results show that the non-blogging student writers wrote more (tokens, types) than the student bloggers did; there were also differences between the two groups of students writing in terms of POS tags in their writing and the results of keyword analysis. However, a closer look at the differences found here suggests no particularly significant variations between the textual information created by the two groups of students. Nevertheless, taken together, the results tend to suggest that classroom blogging had a relatively weaker effect than the conventional teaching approach on Taiwanese EFL student writers.
\end{abstract}

Keywords: blog-aided language learning, classroom blogging, EFL writing

\section{Introduction}

Blogs are an online digital writing and publishing tool for writing journals. They first appeared in the cyberspace community in 1998 (Blood, 2000). In 2003, blogs were introduced to the field of academic writing (Barrios, 2003). Since then, more research and teaching have been conducted to introduce blogs in language classrooms, particularly using blogs as online platforms on which students can engage in journaling writing on various subjects (e.g., Lin, 2015; Lin, in press; Pinkman, 2005; Sun, 2010). This practice has been reported to bring about many positive effects on student writers, such as promoting students' reflective thinking ability, learning motivation, and the command of languages (e.g., Chen, 2016; Holmes \& Moulton, 1995; Lee, 2015; Lin, 2015; Lin, in press; Wong \& Moorhouse, 2018; Xie, Ke, \& Sharma, 2008; Tuan, 2010).

Although blogging a journal has many positive effects, one important aspect that has not yet been exhaustively examined is the specific effects of blogging on the linguistic features generated by student bloggers. With the advent of the World Wide Web (WWW), written languages and genres produced online have been alleged to be different from those produced in the traditional ways that students were used to (Ooi, 2001). One possible reason for this may be audience awareness (cf., Lin, 2015; Lin, in press; Reinhardt, 2019). In blogs, the potential readership is expanded beyond teachers and fellow-students to include anyone with access to the Internet. In addition, "many blogs allow a high degree of interactivity between the audience and author" (Warschauer \& Grimes, 2007, p. 8). As a result, this potentially increased number of genuine online readers may motivate writers or lead them to adopt different writing practices (Roed, 2003; Kitzmann, 2003). In other words, the fact that the blog constitutes a form of public display acts as a kind of incentive for students to be more thoughtful and careful in the content and structure of their postings (Godwin-Jones, 2003). Indeed, some researchers (Crowston \& Williams, 2000; Elola \& Oskoz, 2017; Shepherd \& Watters, 2004) have explored whether new genres or written languages emerged or were adapted on the WWW. Likewise, along with the popularization of blogs over the past few years, some researchers have also shown interest in looking into similar issues, such as analyzing the linguistic and cultural aspects of blog text discourses (e.g., Ooi, Tan, \& Chiang, 2007) or identity and language use (Huffaker \& Calvert, 2005). However, investigations fully focusing on linguistic features so as to evaluate the effects of blogging a journal are rather sparse (Lin, in press). Comparisons between the linguistic features created by regular student writers and those by student bloggers are even scarcer. In this regard, it may 
be helpful to look into the written samples collected from the EFL learners who were taught and write in an online blogging setting, so as to generate further evidence for endorsing or discouraging the teaching of writing through blogs. It would shed greater light by juxtaposing the finding with respect to offline written language produced by an offline group of EFL learners.

For this purpose, one particular method that has not so far been much used to examine the effects of classroom blogging on student writers is to use a corpus approach. This approach, capitalizing on computerized measurements, can generate rich linguistic information that readers might otherwise be unable to observe easily and may thus cast more light on any differences and/or similarities between the online writing samples created by student bloggers and those by non-blogging students. Some specifically helpful linguistic information to look at consists of tokens, types, the type-token ratio (TTR), parts of speech, and lexical features. These are language features in which many researchers nowadays have shown interest (e.g., Fellner \& Apple, 2005; Lin, 2007) and it is believed that to some extent they represent writing proficiency (e.g., Lin, 2015; Lin, in press). As noted by McNeill (2006), a shared assumption among these researchers is that quantitative data such as these can serve as an indicator of students' performance levels in writing.

Accordingly, the aim of this study is to compare the effects of blogging on students' writing performance with those of the traditional face-to-face writing classroom. Specifically, the current researchers aim to determine whether the two groups of students differ in the use of tokens (word count), types, the token-type ratio, parts of speech, and lexical features.

\section{The Study}

\subsection{The Participants}

An 18-week experimental comparison study was conducted on two entire writing classes of English majors from the same department at a university of technology located in central Taiwan. Each class had 25 students, all of 18 or 19 years of age. They were given an information sheet about the experiment and all consented to take part. One of the classes was then randomly assigned to the blogging group (BG) and the other was the control group (CG).

\subsection{Treatment}

The BG met in a computer lab where each student was provided with a PC connected to the Internet. The blogging platform used for this study was Blogger (http://blogger.com). In the first class, the BG students were guided to create their own blogs. Later, from time to time, they were taught how to exercise blog functions to upload journal entries, comment, leave messages, share ideas, add links, post, and revise entries.

Over the course of the experiment, the BG students had to post journal entries every other week. In addition, they posted other assignments and joined collaborative discussions to provide feedback for each other's blog entries. All of these activities were conducted online in their own blogs. Their teacher, one of the current researchers, also left comments on their entries online and uploaded course material, announcements, and videotaped instructions. In addition, all of the students' articles were corrected online, except for writing tests, to avoid peer peeking online (i.e., cheating in this situation).

The CG received the same course material as the BG did, including the same number of assignments and journal entries. However, they had printed forms on which to write, and the same researcher teacher commented and left feedback on these. Furthermore, the students were also asked to peer edit each other's printed journal entries or other writing tasks. The purpose of doing so was to ensure that the two groups had equivalent course material and input.

\subsection{Construction of Corpora}

The collection of student writing texts made up two different corpora in this study for corpus analysis of linguistic data (e.g., tokens, types, lexics, etc.) in students' writing. The two corpora were named the Blogging Group Corpus (BG-Corpus) and the Control Group Corpus (CG-Corpus). According to the syllabus, each participant in each group was expected to contribute 18 pieces of work. These articles included writing assignments, journal entries, and the three different sets of writing tests. The scope of the writing topics mainly included daily events, campus regulations, study aims, and argumentative essays on social events. The word limits for the articles depended on the topics and writing purposes assigned. In general, however, they were asked to write pieces of at least 120 words, 200 words, or 250 words in length and more if they wished. The course design and assignment arrangements made the anticipated number of word tokens for each corpus around 80,000 . This figure may be considered small, but a specialized corpus such as this should be sufficient for the present study. 


\subsection{Data Analysis}

In the data analysis, the current researchers applied three major corpus computing techniques in Wordsmith 5.0: wordlist, keywords, and part-of-speech (POS) tags.

Wordlist. The wordlist function of Wordsmith 5.0 was first used to generate wordlists of the corpora created for this study. This effectively demonstrated the main linguistic features in question: types, tokens, TTR, and even the means of words in sentences. An example of this is illustrated in the figure below (Figure 1).

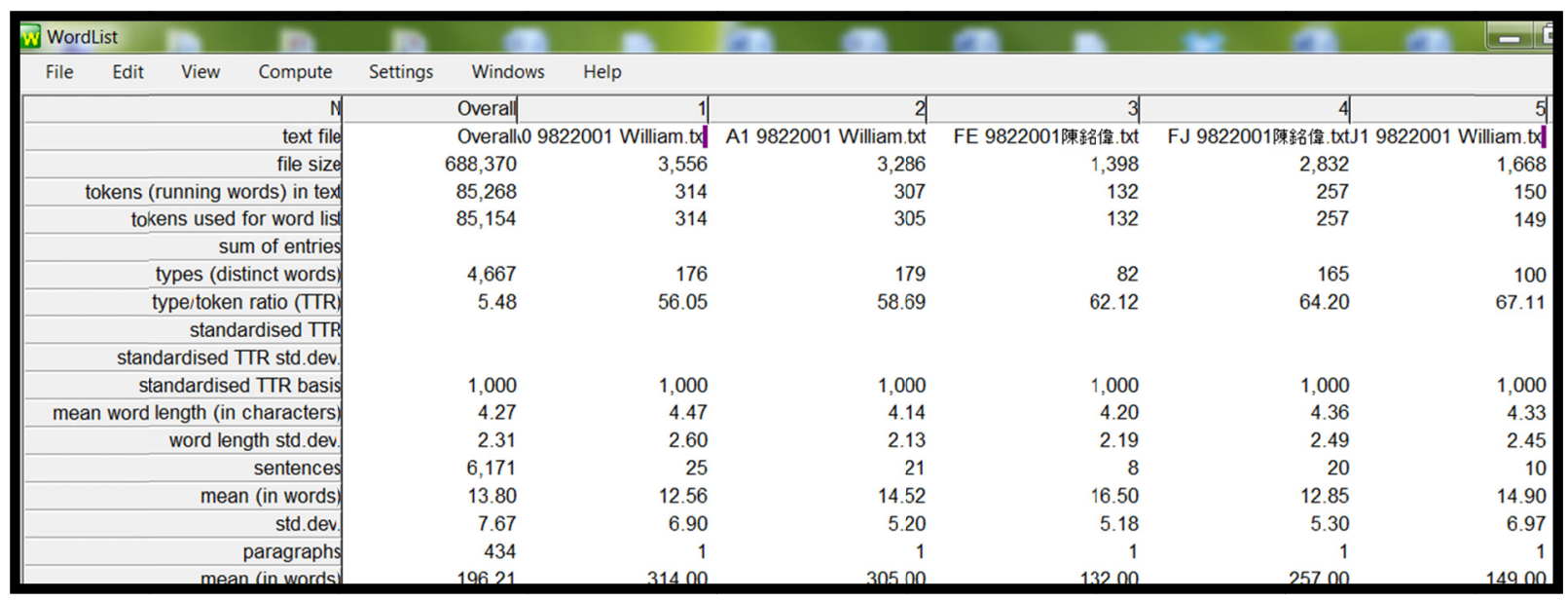

Figure 1. Descriptive statistical display of wordlist in Wordsmith 5.0

Keywords. Another important function of Wordsmith 5.0 was computing keywords, to display any significant variation in vocabulary between two corpora. The aim of the keywords procedure is to use automatic methods to identify key words that are statistically significantly associated with a particular specialized corpus (see an example in Figure 2). In turn, keywords can often be used to indicate the characteristic style of a particular text or corpus (Scott \& Tribble, 2006).

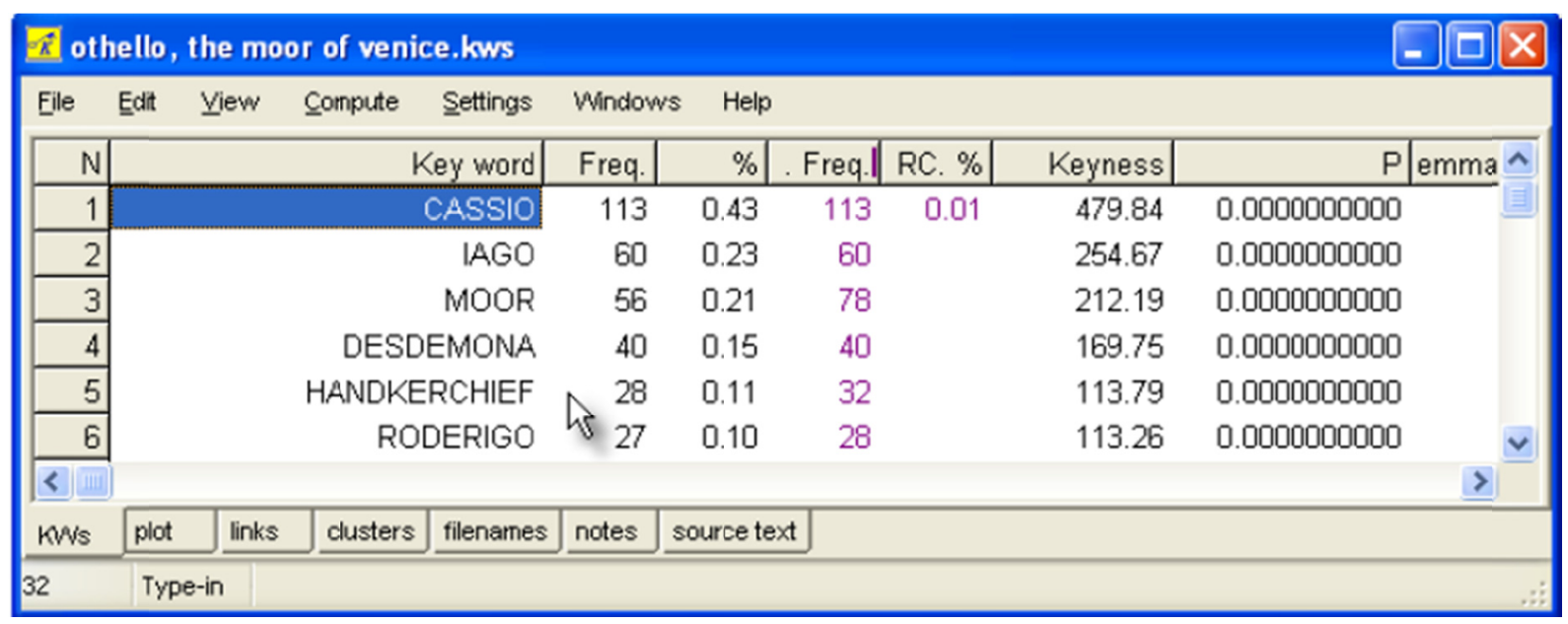

Figure 2. Display of keywords

The first step in the keywords procedure is to recruit two pre-existing wordlists, one of which is usually a large wordlist acting as a reference file, while the other is the target wordlist of study. In this study, the British National Corpus (BNC) was used as a reference wordlist for comparison with the BG-Corpus and the CG-Corpus. The results of this cross-comparison can explain relatively objectively whether the two corpora 
differ in any way from each other. The BNC is a compilation of nearly 100 million words from a wide range of sources, containing both written $(90 \%)$ and spoken $(10 \%)$ examples. Since this thesis examines student writing corpora, only the written part of the BNC (around 90 million words) will be used for comparative reference. More information in detail about the building of the BNC can be accessed here: www.natcorp.ox.ac.uk, while the BNC wordlist can be downloaded here: www.lexically.net/downloads/version4/downloading\%20BNC.htm. In addition to the regular use of a large wordlist as a reference file, a comparison was also made between the BG-Corpus and the CG-Corpus as reference wordlists for each other.

POS tags. POS tags illustrate grammatical tagging, assigning a syntax class, such as noun, verb, preposition, or article to every word in a text. For example, desk would usually be tagged as a noun, while see is tagged as a verb. For convenience, a series of abbreviations is used for the tags. For example, nouns would be NN, verbs are usually VV, and prepositions are PRP. However, different sets of POS tags are developed, primarily depending on the number of grammatical features that the developers want to include, as a result of which NN will be tagged as NN1, for example, for singular nouns or NN2 for plural noun. A sentence with annotations would usually look like this: Celebrities_NN2 need_VV0 paparazzi_NN2 to_TO become_VVI famous_JJ._. The tagging was then done with the CLAWS POS Tagger for English (http://ucrel.lancs.ac.uk/claws/trial.html). CLAWS was chosen mainly because of its consistently achieved accuracy of $96-97 \%$, although a small error-rate of about $1.5 \%$ and ambiguities of $3.3 \%$ may be expected to occur. Two sets of CLAWS tagging service are available: C5 (ucrel.lancs.ac.uk/claws5tags.html) and C7 (ucrel.lancs.ac.uk/claws7tags.html). The C5 contains 62 part-of-speech (POS) tags while the C7 can identify 137. The latter was chosen for this study because its more fine-grained features were expected to yield more detailed information than the former's. Upon the completion of annotations, Wordlist in Wordsmith 5.0 was then used again to compute the number of each of the POS tags. The POS tags were then compared using the normalized frequency of 10,000 rather than raw frequencies. The reason for this was that the size of the corpora was only around 80,000 words. A frequency of 100,000 and over could have made the computed figures seem too trivial to matter, whereas a base of 1,000 or less might have amplified the observations unduly. Under the 10,000-word based normalized frequencies, the researchers considered a difference of 10 per 10,000 words between the two corpora to be worth noting as observable. POS tag frequency differences of less than 10 per 10,000 words were not discussed because such information was too limited to analyze.

\section{Results and Discussion}

Wordsmith 5.0 was used to calculate the size of the corpora and to display some basic information about them, the result of which is summarized in Table 1 and reported as follows. A total of 408 pieces of writing was collected in the BG-Corpus, on average 16.32 pieces per student. The size of the BG-Corpus equates to 85,268 running words of text, developed from 4,667 types (distinct words), which gave a TTR of 5.48\%. On average, each article was of around 208 words. The CG students created a slightly larger corpus than the BG, that is, 89,415 tokens and 4,840 types (TTR $=5.66 \%$ ). The mean article length was about 219 words. Both corpus sizes met the anticipated total number of tokens of 80,000 .

Table 1. Profiles of the BG-Corpus and the CG-Corpus

\begin{tabular}{lll}
\hline & Blogging Group Corpus & Control Group Corpus \\
\hline Total student writers & 25 & 25 \\
Total text files & 408 & 408 \\
Text files per student & 16.32 & 16.32 \\
Total Tokens (running words) & 85,268 & 89,415 \\
Tokens per article & 208.99 & 219.15 \\
Types (distinct words) & 4667 & 4840 \\
Type/token ration (TTR) & 5.48 & 5.66 \\
\hline
\end{tabular}

\subsection{Tokens, Types, TTR, and Words Per Sentence (W/S) Results and Implications}

Table 2 shows that all of the basic data in the CG-Corpus exceeded those of the BG-Corpus although both groups, as previously mentioned, contributed the same number of pieces of writing to the corpora. The CG produced 4,157 words more than the Control Group, meaning that, on average, each individual in the CG wrote an extra 10 words per article (this is calculated and presented as 'tokens per article' in Table 2). The specific reasons for this are uncertain at this stage; at this juncture, it seems premature to claim it as an indicator of relatively skilled writing performance for the CG. However, it may be appropriate to suggest that the ten more 
words per article indicate that the CG participants were more willing to make an effort to compose a relatively lengthy article (to better clarify their ideas, perhaps).

In addition to tokens, the BG used slightly fewer word types by 173 words than the CG did, a lower TTR by .018 , fewer sentences by 21 , and fewer W/S by .61. Although these figures are considered small, the consistency with which the CG-Corpus exceeded the BG-Corpus overall increased it to a sufficient size. In turn, this may lend some support to the implication that students in the CG produced slightly richer language information in their work than those in the BG. Perhaps this in a way indicates that the CG developed better writing performance in terms of content than the BG students. However, this idea should be taken with great caution, because richer content does not necessarily represent better writing skills. Whether or not such numerical counts really represent student writing performance levels will still require more evidence, on which the results shown below may shed some light.

Table 2. Basic data of the BG-Corpus and the CG-Corpus

\begin{tabular}{llll}
\hline & BG-Corpus & CG-Corpus & BG-CG \\
\hline Total Tokens (running words) & 85,268 & 89,415 & $-4,157$ \\
Tokens per article & 209 & 219 & -10 \\
Types (distinct words) & 4,667 & 4,840 & -173 \\
Type/token ration (TTR) & 5.48 & 5.66 & -0.18 \\
Sentences & 6,171 & 6,192 & -21 \\
Words per sentence & 13.80 & 14.41 & -0.61 \\
\hline
\end{tabular}

\subsection{POS Tag Results and Implications}

Based on the set frequency standard of identifying a difference of 10 per 10,000 words, a great similarity of over $87 \%$ was found between the two corpora in terms of POS annotation, Namely, the frequencies of 121 items among the 137 were less than 10 per 10,000. Additionally, overall $57 \%$ of the 137 pieces of annotation had nearly identical frequencies of less than or equal to 1 per 10,000 tags. It is likely that this similarity was the result of the same writing topics being assigned to both groups, but it can also suggest that the online writing environment barely creates sufficient impact to change students' choices of vocabulary.

The items of different frequencies of at least 10 per 10,000 words between the corpora are shown in Table 3 and are few in number in comparison to the revealed similarity. Overall, 17 pieces of annotation were identified, the frequency differences ranging from 10 to 38 per 10,000 words. They were AT, AT1, CCB, DA2, II, JJ, NN1, NN2, NP1, PN1, PPHS2, PPIS2, TO, VBZ, VDI, VVI, and VVZ (the meanings of the abbreviations are attached as notes to Table 3). The BG-Corpus contained more annotation in terms of AT1, NN1, VBZ, VVZ, CCB, JJ PN1, and PPHS2, while the CG-Corpus had more AT, NN2, TO, VDI, VVI, DA2, II, NP1, and PPIS2.

Some of the differences in annotation found here are seen to result from one another. For example, because the CG-Corpus had more singular nouns (NN1) and singular indefinite pronouns (PN1), relatively higher frequencies of singular articles (AT1), -s forms of lexical verbs (VVZ, e.g., gives, works), and is (VBZ) are concurrently involved. Similarly, the BG-Corpus embraces more plural common nouns (NN2, e.g., books, girls) and, therefore, fewer VBZ, AT1, and VVZ are found. The relatively frequent use of AT (e.g., the) and DA2 (plural after-determiner) in the BG-Corpus also apparently corresponds to the use of NN2. This observation seems trivial on the surface, but it leads to an interesting question: When the two groups dealt with the same writing topics, why would one group have preferred to use (significantly) more singular nouns whereas the other group favored the use of plural nouns? Could this serve as a sign suggesting different levels of linguistic understanding of the use of nouns or definite and indefinite articles? This assumption seems reasonable, since most Mandarin Chinese speakers find it difficult to select proper generic reference (a/the/no articles) (Robertson, 2000; Snape, Mayo, \& Gürel, 2009). In this respect, it can be anticipated that advanced Chinese learners of English would be able to use English articles more accurately. Further investigation on this is possible by using concordances.

In addition to the use of nouns and articles, a greater number of general adjectives (JJ) and 3rd person plural subjective personal pronouns (PPHS2, i.e., they) are used in the CG-Corpus, whilst in the BG-Corpus there are more general prepositions (annotated as II), 1st person plural subjective personal pronouns (PPIS2, i.e., we), and singular proper names (NP1, e.g., China, John, McDonald's). In terms of JJ, it seems reasonable to argue again that the CG-Corpus is composed of student work of a slightly richer description than the BG-Corpus. This implication is also supported when closely examining the 'JJ-TTR' by itself. The JJ-TTR is the total JJ tokens 
divided by total $\mathrm{JJ}$ types. The total number of $\mathrm{JJ}$ tokens for the BG-Corpus is 5,037 and the number of $\mathrm{JJ}$ types is 688 . The total number of JJ tokens for the CG-Corpus is 5,499, subject to $820 \mathrm{JJ}$ types. This shows that the CG-Corpus has a higher degree of density than the BG-Corpus by $1.26 \%$ (see Table 4 ).

Table 3. The normalized frequency differences between the BG-Corpus and the CG-Corpus

\begin{tabular}{llllll}
\hline & BG-CORPUS & CG-CORPUS & BG - CG \\
\hline Annotation $^{*}$ & Raw fre. & Normalized fre. per 10,000 & Raw fre. & Normalized fre. per 10,000 & Differences per 10,000 \\
\hline NN1 & 11471 & 1371 & 12280 & 1398 & -27 \\
AT1 & 1761 & 210 & 2180 & 248 & -38 \\
VBZ & 1767 & 211 & 2023 & 230 & -19 \\
VVZ & 387 & 46 & 493 & 56 & -10 \\
CCB & 460 & 55 & 666 & 76 & -21 \\
JJ & 5037 & 602 & 5499 & 626 & -24 \\
PN1 & 442 & 53 & 576 & 66 & -13 \\
PPHS2 & 687 & 82 & 825 & 94 & -12 \\
NN2 & 3481 & 416 & 3408 & 388 & 28 \\
AT & 3400 & 406 & 3323 & 378 & 28 \\
TO & 2642 & 316 & 2656 & 302 & 13 \\
VDI & 310 & 37 & 240 & 27 & 10 \\
VVI & 4389 & 524 & 4413 & 502 & 22 \\
DA2 & 533 & 64 & 404 & 46 & 18 \\
II & 4231 & 506 & 4160 & 473 & 32 \\
NP1 & 672 & 80 & 537 & 61 & 19 \\
PPIS2 & 997 & 119 & 881 & 100 & 19 \\
\hline
\end{tabular}

*Note. The abbreviations in order are explained as follows: AT: article (e.g., the, no) // AT1: singular article (e.g., a, an, every) // CCB: adversative coordinating conjunction (but) // DA2: plural after-determiner (e.g., few, several, many) // II: general preposition // JJ: general adjective // NN1: singular common noun (e.g., book, girl) // NN2: plural common noun (e.g., books, girls) // NP1: singular proper noun (e.g., London, Jane, Frederick) // PN1: indefinite pronoun, singular (e.g., anyone, everything, nobody, one) // PPHS2: $3^{\text {rd }}$ person plural subjective personal pronoun (they) // PPIS2: $1^{\text {st }}$ person plural subjective personal pronoun (we) // TO: infinitive marker (to) // VBZ: is // VDI: do, infinitive (I may do...To do...) // VVI: infinitive (e.g., to give...it will work...) // VVZ: -s form of lexical verb (e.g., gives, works).

Table 4. The normalized frequency differences between the BG-Corpus and the CG-Corpus in terms of JJ (general adjectives)

\begin{tabular}{|c|c|c|c|c|c|c|c|}
\hline \multirow{3}{*}{$\begin{array}{l}\text { Annotation } \\
\text { Number }\end{array}$} & \multicolumn{3}{|c|}{ BG-CORPUS } & \multicolumn{3}{|c|}{ CG-CORPUS } & \multirow{2}{*}{$\begin{array}{l}\mathrm{BG}-\mathrm{CG} \\
\text { JJ-TTR }\end{array}$} \\
\hline & JJ tokens & JJ types & JJ-TTR & $\mathrm{JJ}$ tokens & JJ types & JJ-TTR & \\
\hline & 5,037 & 688 & $13.65 \%$ & 5,499 & 820 & $14.91 \%$ & $1.26 \%$ \\
\hline
\end{tabular}

Table 5 reveals more NP1, II, and PPIS2 in the BG-Group, but this suggests little about students' writing skills. The data were primarily skewed by two 'trips' that BG students took during their first winter vacation in college. A group of more than 10 student writers went on the same trip to a city in Taiwan called Kaohsiung and nearly half of them mentioned or talked about this in their first journal entry, S2J1 (Semester 2, Journal 1). In the same journal assignment, two of the students wrote about a trip that they took to Thailand. It should be noted here that S2J1 was not designated for students to talk about their travels. Rather, the journal required students to reflect on their winter vacation, so when these students focused on their trips, the data were skewed. In these reflections by students on their trip, the name of the city-Kaohsiung - and the country-Thailand (NP1) were mentioned frequently, as a result of which the number of general prepositions (II), such as to Kaohsiung, in Kaohsiung, at Kaohsiung, or went to Kaohsiung with somebody, also slightly increased. Consequently, NPI and II increased significantly in the data. In the journals, the student writers tended to talk about the trip experience using the 1st person plural subjective personal pronoun we (as a group), thus amplifying the use of PPIS2. To examine this observation further, the normalized frequency of NP1, II, and PPIS2 by 10,000 (for reading convenience) and in journals S2J1 by itself for both groups was calculated. The results confirmed this observation. For a similar reason, the different frequencies of the use of PPHS2 may have been influenced by some writing topic choices.

A more frequent use of CCB (namely, adversative coordinating conjunction but) was found, but it does not suggest much about students' writing performance, either. It is likely to have resulted mainly from preference. Other words with similar meanings to CCB were used in the BG-Corpus than in the CG-Corpus, such as nevertheless, however, though, even though, although and yet. These words are tagged as either RR or CS (i.e., 
general adverbs or subordinating conjunction), rather than CCB. Table 6 illustrates a fine comparison of this scenario. (It should be noted that only those RR and CS which are similar to but in terms of meanings are calculated here.) Although but is found more often in the CG-Corpus, in the BG-Corpus nearly all of the rest of the items are more frequently used. In comparing the total normalized frequency, the difference between the two corpora dropped from 21 per 10,000 in terms of CCB only to 8.22 per 10,000 through CCB and the related RR, and CS.

Table 5. Frequency differences between the BG-Corpus and the CG-Corpus in terms of NP1, PPIS2, and II

\begin{tabular}{llllll}
\hline & \multicolumn{2}{l}{ BG-CORPUS } & CG-CORPUS & BG - CG \\
\hline Annotation & Raw fre. & $\begin{array}{l}\text { Normalized fre. } \\
\text { per 10,000 words }\end{array}$ & Raw fre. & $\begin{array}{l}\text { Normalized fre. } \\
\text { per 10,000 words }\end{array}$ & $\begin{array}{l}\text { Differences } \\
\text { per 10,000 }\end{array}$ \\
\hline NP1 & 104 & 178.3 & 49 & 82.2 & 96.1 \\
PPIS2 & 148 & 253.8 & 80 & 134.2 & 119.5 \\
II & 344 & 589.9 & 337 & 565.6 & 24.3 \\
Total & 5,831 & 10,000 & 5,958 & 10,000 & N/A \\
\hline
\end{tabular}

Table 6. Frequency differences between the BG-Corpus and the CG-Corpus in terms of CCB, CS, and RR

\begin{tabular}{llll}
\hline & BG-CORPUS & CG-CORPUS & BG - CG \\
\hline Items and Annotations & Raw fre. & Raw fre. & Frequency 10,000 \\
\hline although & 88 & 78 & -1.63 \\
but & 460 & 666 & 21 \\
even though/though & 40 & 57 & 1.70 \\
however & 174 & 82 & -11.46 \\
nevertheless & 20 & 11 & -1.13 \\
yet & 4 & 2 & -0.25 \\
TOTAL & 786 & 896 & -8.22 \\
\hline
\end{tabular}

\subsection{The Results and Implications of Keywords}

The BG-Corpus vs. the CG-Corpus. A total of 15 words stood out in the keywords when the CG-Corpus wordlist was used as a reference (Table 7), while 19 words in total were found to reach the log likelihood significant level when the BG-Corpus wordlist served as a reference (Table 8). However, like the POS tag results, the difference in word usage in terms of keyword technique did not reveal many remarkable observations of students' writing performance, either. As reasoned earlier, some of the highly frequent annotation was skewed because of some student writers' topic choices or word preferences, thus yielding no significant observations. For a similar reason, some words stood out: guitar, ride, riding, and bike. For example, all the recurrences of guitar (27 times) were produced by one BG student writer who joined a church band where he played the guitar. An observable, significantly larger set of words-bicycle, ride, riding, and bike - was found in the BG-Corpus mainly because of the only different writing topic assigned to them, which asked students to reason why the popularity of cycling has recently increased. In the meantime, a different topic was igned to the Control Group on the phenomenon of young people's living together, which is why vocabulary about cohabitation was mostly found only in the CG-Corpus: cohabitation, cohabit, married, lover, and marry (see Table 8). In this regard, words as such are not worth further discussion (Barlow, 2005, p. 14). In addition to the issues of choices and preferences, the frequency of some keywords, such as instance and felt, is so low that they hardly provide much meaningful information, either. Additionally, the results regarding the differences of the, however, $a$, and many are discussed above in the POS tagging section and so will not be repeated here. Therefore, it can be put forward that the blogging approach had no significant influence on students' writing performance in terms of word choice. 
Table 7. Keywords: the BG-Corpus wordlist in comparison to the CG-Corpus wordlist

\begin{tabular}{llllllll}
\hline $\mathrm{N}$ & Key word & Freq. & $\%$ & RC. Freq. & RC. $\%$ & Keyness & P \\
\hline 1 & BICYCLE & 111 & 0.130 & 5 & & 124.75 & $1.0703 \mathrm{E}-15$ \\
2 & RIDE & 88 & 0.103 & 9 & 0.01 & 78.38 & $9.1509 \mathrm{E}-15$ \\
3 & RIDING & 62 & 0.072 & 4 & & 64.12 & $2.9254 \mathrm{E}-14$ \\
4 & THE & 3348 & 3.926 & 2999 & 3.35 & 40.83 & $2.5043 \mathrm{E}-12$ \\
5 & HOWEVER & 174 & 0.204 & 82 & 0.09 & 38.38 & $9.5063 \mathrm{E}-12$ \\
6 & GUITAR & 27 & 0.031 & 1 & & 31.44 & $1.7618 \mathrm{E}-08$ \\
7 & BIKE & 34 & 0.039 & 4 & & 28.55 & $8.8052 \mathrm{E}-08$ \\
8 & MANY & 502 & 0.588 & 375 & 0.41 & 25.10 & $5.3936 \mathrm{E}-07$ \\
9 & INSTANCE & 28 & 0.032 & 3 & & 24.47 & $7.5123 \mathrm{E}-07$ \\
10 & A & 1532 & 1.796 & 1916 & 2.14 & -27.09 & $1.9068 \mathrm{E}-07$ \\
11 & IT'S & 75 & 0.087 & 162 & 0.18 & -28.73 & $8.0035 \mathrm{E}-08$ \\
12 & M & 13 & 0.015 & 59 & 0.06 & -29.67 & $4.8067 \mathrm{E}-08$ \\
13 & FELT & 22 & 0.025 & 78 & 0.08 & -30.66 & $2.7798 \mathrm{E}-08$ \\
14 & BUT & 465 & 0.545 & 685 & 0.76 & -32.76 & $7.4899 \mathrm{E}-09$ \\
15 & NOT & 457 & 0.535 & 720 & 0.80 & -47.75 & $3.0715 \mathrm{E}-13$ \\
\hline
\end{tabular}

Table 8. Keywords: the CG-Corpus wordlist in comparison to the BG-Corpus wordlist

\begin{tabular}{llllllll}
\hline $\mathrm{N}$ & Key word & Freq. & $\%$ & RC. Freq. & RC. $\%$ & Keyness & P \\
\hline 1 & COHABITATION & 64 & 0.07 & 0 & & 85.74 & $5.78 \mathrm{E}-15$ \\
2 & COHABIT & 43 & 0.05 & 0 & & 57.60 & $6.08402 \mathrm{E}-14$ \\
3 & MARRIED & 43 & 0.05 & 1 & & 49.49 & $2.1519 \mathrm{E}-13$ \\
4 & NOT & 720 & 0.81 & 457 & 0.54 & 47.76 & $3.0715 \mathrm{E}-13$ \\
5 & LOVER & 32 & 0.04 & 1 & & 35.34 & $3.34744 \mathrm{E}-10$ \\
6 & BUT & 666 & 0.77 & 460 & 0.55 & 32.76 & $7.48987 \mathrm{E}-09$ \\
7 & FELT & 78 & 0.09 & 22 & 0.03 & 30.66 & $2.77984 \mathrm{E}-08$ \\
8 & M & 59 & 0.07 & 13 & 0.02 & 29.68 & $4.80673 \mathrm{E}-08$ \\
9 & IT'S & 162 & 0.18 & 75 & 0.09 & 28.74 & $8.00349 \mathrm{E}-08$ \\
10 & A & 1916 & 2.14 & 1532 & 1.80 & 27.10 & $1.90685 \mathrm{E}-07$ \\
11 & MARRY & 23 & 0.03 & 1 & & 23.93 & $9.96823 \mathrm{E}-07$ \\
12 & INSTANCE & 3 & & 28 & 0.03 & -24.47 & $7.51229 \mathrm{E}-07$ \\
13 & MANY & 375 & 0.42 & 502 & 0.59 & -25.11 & $5.39357 \mathrm{E}-07$ \\
14 & BIKE & 4 & & 34 & 0.04 & -28.56 & $8.8052 \mathrm{E}-08$ \\
15 & HOWEVER & 82 & 0.09 & 174 & 0.20 & -38.38 & $9.50625 \mathrm{E}-12$ \\
16 & THE & 2999 & 3.35 & 3348 & 3.93 & -40.84 & $2.50427 \mathrm{E}-12$ \\
17 & RIDING & 4 & & 62 & 0.07 & -64.13 & $2.92538 \mathrm{E}-14$ \\
18 & RIDE & 9 & 0.01 & 88 & 0.10 & -78.38 & $9.15092 \mathrm{E}-15$ \\
19 & BICYCLE & 5 & & 111 & 0.13 & -124.75 & $1.07026 \mathrm{E}-15$ \\
\hline
\end{tabular}

The BG-Corpus and the CG-Corpus vs. the BNC. This section presents the results of the analysis keywords in the BG-Corpus (BGC), the CG-Corpus (CGC), and the BNC. Two sets of cross-comparisons were carried out: (1) the $\mathrm{BGC}$ vs. the $\mathrm{BNC}$ and the $\mathrm{CGC}$ vs. the $\mathrm{BNC}$; and (2) the BNC vs. the BGC and the BNC vs. the CGC (see Figure 3 for an illustration). The corpus placed after the 'vs.' sign is used as a reference file. Long lists of keywords results were yielded but were reduced to the top 20 representing the syntax classes of these corpora, the results of which are presented in Table 9. (However, Table 9 consists only of the results of 'keywords'.)

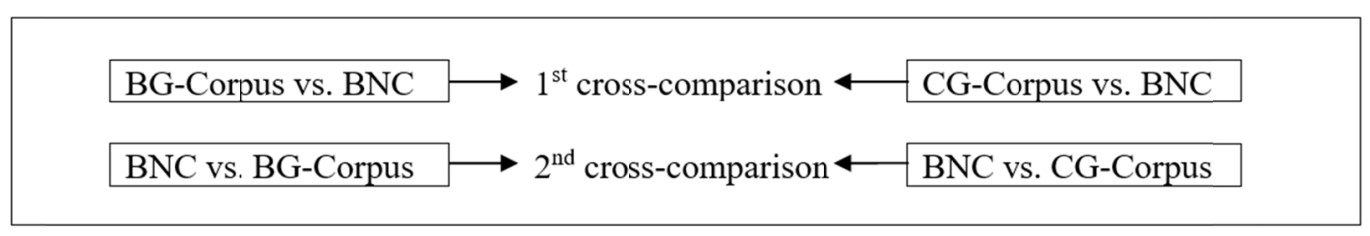

Figure 3. Cross-comparisons between the BG-Corpus, the CG-Corpus, and the BNC 
As Table 9 shows, the first set of the cross-comparison of the BG-Corpus vs. BNC and CG-Corpus vs. BNC has an overlap of 18 items in the top 20 (i.e., 90\%) although their rankings are slightly different. Only four different key words were found in the first set of cross-comparisons: Chaoyang (the name of a university) and many in the pair of the BG-Corpus vs. the BNC, and celebrities and you in the results of CG-Corpus vs. the BNC. It is clear that the results of the cross-comparison yielded no significant differences between the two student corpora, either. This suggests, on the one hand, that both the BG and the CG contained the same application of linguistic features and that, on the other, there was non-significant blogging impact on the students' use of syntax in writing. Alternatively, it is interesting to note that the higher frequency of use of you found in the CG in comparison to the BG may suggest that the CG students had only a single major audience to address, that is, the research lecturer. This suggests that the BG students may have been mindful of the fact that they were blogging to a wider audience.

In terms of the ratio of overlapping keywords, a similar result ( $90 \%$ overlapping) is found for the second set of cross-comparisons of the BNC vs. the BG-Corpus and the BNC vs. the CG-Corpus. Two different items $\mathrm{Mr}$ and an were found in the BNC vs. the BG-Corpus, whereas two others that stood out in the BNC vs. the CG-Corpus were $b y$ and $a s$. Interestingly, $90 \%$ of the top 20 items in the second cross-comparison are all function words, including the, he, his, her, was, its, been, had, were, which, she, at, him, an, by, as and into. The results may also suggest that no observable differences were found between the writing styles of the BGC and the CGC.

In addition to the main findings about the difference between the two writing corpora, it was found that, in comparison to the BNC, both groups' participants tended to over-use the first person pronouns (i.e., $I, m y$, and $w e$ ), as shown in the first cross-comparison, and to under-use third person narrations, as found in the second cross-comparison. Although this may imply that the participants were less able to discuss more objectively from the standpoint of a third party, it seems that the results are mainly biased by the fact that both of the BG-Corpus and the CG-Corpus comprised a great number of reflective journaling samples, which are usually narrated in the first person. The fact that students were asked to write about their personal opinions on social issues was also to a large extent likely to contribute to this. This being the case, 'over-use' here is likely to be more indicative of the genre in which students were writing than of any peculiarities of the students' written English in general. If anything, what it suggests is that these students were able to write appropriately in this genre, at least in terms of making appropriate grammatical person selections for their blog posts.

Table 9. Keywords results: Cross-comparisons between the BGC, CGC and the BNC

\begin{tabular}{|c|c|c|c|c|}
\hline & \multicolumn{2}{|c|}{ 1st cross-comparison } & \multicolumn{2}{|c|}{ 2nd cross-comparison } \\
\hline & BGC vs. BNC & CGC vs. BNC & BNC vs. BGC & BNC vs CGC \\
\hline $\mathrm{N}$ & Keyword & Keyword & Keyword & Keyword \\
\hline 1 & I & I & $\#$ & \# \\
\hline 2 & MY & PAPARAZZI & OF & THE \\
\hline 3 & PAPARAZZI & MY & THE & OF \\
\hline 4 & ENGLISH & CAN & $\mathrm{HE}$ & $\mathrm{HE}$ \\
\hline 5 & CAN & SEMESTER & HIS & HIS \\
\hline 6 & THINK & THINK & HER & WAS \\
\hline 7 & WE & ABORTION & WAS & HAD \\
\hline 8 & LEARN & LABOR & ITS & HER \\
\hline 9 & SEMESTER & TRAVEL & BEEN & BEEN \\
\hline 10 & CHAOYANG* & ENGLISH & HAD & ITS \\
\hline 11 & ABORTION & BACKPACKING & WERE & SHE \\
\hline 12 & LABOR & VACATION & QUOT & WERE \\
\hline 13 & PEOPLE & LEARN & WHICH & $\mathrm{AT}$ \\
\hline 14 & TRAVEL & WE & SHE & $\mathrm{BY}^{* *}$ \\
\hline 15 & VACATION & $\mathrm{T}$ & AT & QUOT \\
\hline 16 & MANY* & WANT & HIM & $\mathrm{AS}^{* *}$ \\
\hline 17 & BECAUSE & CELEBRITIES* & INTO & INTO \\
\hline 18 & $\mathrm{~T}$ & BECAUSE & $\mathrm{MR}^{* *}$ & SAID \\
\hline 19 & WANT & PEOPLE & SAID & HIM \\
\hline 20 & BACKPACKING & YOU* & $\mathrm{AN}^{* *}$ & WHICH \\
\hline
\end{tabular}

Note 1. $\mathrm{BGC}=$ Blogging Group Corpus; $\mathrm{CGC}=$ Control Group Corpus; $\mathrm{BNC}=$ British National Corpus.

Note 2. The corpus placed after the 'vs.' sign is used as a reference file. * The only differences in the top 20 items between the BGC vs. BNC and the CGC vs. the BNC. **The only differences in the top 20 items between the BNC vs. BGC and the BNC vs. the CGC. 


\section{Further Discussion}

This study examined the effects of blogging on students' writing performance by means of a corpus approach. It looked at similarities and differences between the BG-Corpus and the CG-Corpus using a series of corpus numerical counts: tokens, types, TTR, and words per sentence. Keywords and POS tags were also considered in this task. The results show that, in terms of types, TTR, and W/S, the CG-Corpus contains slightly richer language information than the BG-Corpus. At most, the greater number of tokens produced on average in the CG-Corpus may be indicative of greater motivation on the part of the CG students to write, rather than greater linguistic skills, as assumed by previous researchers (e.g., Fellner \& Apple, 2006).

The results of analyzing the keywords and the POS tags analyses make it reasonable to suggest that a blog assisted language learning environment can exert only a very limited effect on Taiwanese EFL students' writing performance in terms of lexis or syntax, because no meaningful differences in comparison to the $\mathrm{CG}$ were observed. The triangulation examination of BG-Corpus, CG-Corpus, and BNC alone also showed no evidential difference. All of these also confirm that the online writing environment failed to allow the 'online writing literacy' suggested by Ooi (2001) and Ooi, Tan, and Chiang (2007) to develop. A possible explanation for this may relate to the fact that the students have long been exposed to an Internet-dominated world where online applications change rapidly. Students are so used to the fast pace of technological change that integrating an additional online environment into their academic studies may no longer have the influential impact that it perhaps used to have.

Some may think that the insignificant differences found in keywords or POS tags are likely to be caused by the fact that these two areas yield inadequate measurements for determining students' writing levels in the first place, since it is not the main purpose for which these two areas were created. However, this assumption is far from the truth, since the results are in line with previous observations drawn from the human rater's scores where the writing of both groups was found to be significantly similar, except for its content. The difference between the two groups in terms of article content, however, is also to some extent supported by the POS JJ tag results. This does not suggest that these results be taken at this point as a sign that POS tags and keywords may indicate students' writing abilities, especially given that the practice was as yet limited to two groups of student writing samples. Future investigations may enhance the understanding of and evidence for this.

Finally, as seen earlier, function words in both the BG-Corpus and the CG-Corpus were not used as frequently as they were in the BNC, where the samples came from the work of English native speakers. As argued earlier, the more limited use of third person pronouns mostly resulted from the sample collection alone. However, the rest of the function words may still be seen as a sign that both groups' English writing styles have not yet developed to a level close to that of English native speakers. This is particularly evident when it is taken into account that (a) keywords can be useful indicators of the characteristic style of a particular corpus, and that (b) function words can discriminate stylistic text attribution (Argamon \& Levitan, 2005). It would be inadequate, however, to use this finding to conjecture that the course of English writing conducted for this experimental project failed at its task. Rather, the results indicate that the productive use of function words needs more attention in the EFL writing classroom (cf., Willis, 1990; Thornbury, 2004a, 2004b).

\section{Concluding Remarks}

This study took a corpus approach to analyze the writing samples collected from both student bloggers and those who received no blogging treatment, with the aim of further determining whether the two groups of students wrote differently. It was expected that any similarities and differences found in the linguistic features of their writing might shed light on the effects of the blogging approach. With the findings addressed above, it is clear that this study has been broadly successful in this stated aim and the main study focus. First, the current researchers have made a case for using the selected corpus linguistic methods-POS tags and keyword analysis, in particular - to classify the two groups' writing samples. As has been seen, a significantly weak writing skill for Taiwanese EFL students was revealed, namely, the underuse of a group of function words. Moreover, the overall findings in this study serve as a triangulation that lends great support to the claim that classroom blogging is perhaps not so effective a teaching approach as to change students' writing styles or skills. This being said, however, it must be acknowledged that the study has certain limitations that await contributions from future reserachers. For example, students' learning preferences were not taken into consideration in this study. Looking into this aspect may cast different light on the effects of blogging since learner profiles are generally believed to have a corresponding effect with different pedagogies (cf., Lin, 2016). Additionally, the corpora built for this study may seem insufficient to rigorous corpus linguists. Future studies may thus consider establishing larger corpora to further assess the effects of blogging on student writers' textual output. 


\section{Acknowledgements}

This article was written with funding support from Taiwan's Ministry of Science and Technology (MOST 104-2410-H-032-051; MOST 107-2410-H-032-057).

\section{References}

Argamon, S., \& Levitan, S. (2005). Measuring the usefulness of function words for authorship attribution. In Proceedings of ACH/ALLC 2005, Association for Computing and the Humanities, Victoria, BC.

Barlow, M. (2005). Computer-based analyses. In R. Ellis \& G. Barkhuizen (Eds.), Analysing Learner Language (pp. 335-369). Oxford: Oxford University Press.

Barrios, B. (2003). The year of the blog: Weblogs in the writing classroom. Retrieved 26 October, 2008, from http://www.bgsu.edu/cconline/barrios/blogs/

Blood, R. (2002). The Weblog handbook: Practical advice on creating and maintaining your blog. Cambridge, MA: Perseus Publishing.

Chen, P.-J. (2016). Learners' metalinguistic and affective performance in blogging to write. Computer Assisted Language Learning, 29(4), 790-814. https://doi.org/10.1080/09588221.2015.1068813

Crowston, K., \& Williams, M. (2000). Reproduced and emergent genres of communication on the World Wide Web. The Information Society, 16, 201-216. https://doi.org/10.1080/01972240050133652

Elola, I., \& Oskoz, A. (2017). Writing with 21 st century social tools in the L2 classroom: New literacies, genres, and writing practices. Journal of Second Language Writing, 36, 52-60. https://doi.org/10.1016/j.jslw.2017.04.002

Fellner, T., \& Apple, M. (2006). Developing writing fluency and lexical complexity with blogs. The JALT CALL Journal, 2(1), 15-26.

Godwin-Jones, B. (2003). Blogs and wikis: environments for online collaboration. Language Learning \& Technology, 7(2), 12-16.

Holmes, V. L., \& Moulton, M. R. (1995). A contrarian view of dialogue journals: The case of a reluctant participant. Journal of Second Language Writing, 4(3), $223-251$. https://doi.org/10.1016/1060-3743(95)90011-X

Huffaker, D. A., \& Calvert, S. L. (2005). Gender, identity, and language use in teenage blogs. Journal of Computer-Mediated Communication, 10(2). Retrieved 17 February, 2009, from http://jcmc.indiana.edu/vol10/issue2/huffaker.html

Kitzmann, A. (2003). That different place: Documenting the self within online environments. Biography, 26(1), 48-65. https://doi.org/10.1353/bio.2003.0026

Lee, S. Y. (2015). Joining the 'literacy club': When reading meets blogging. ELT Journal, 69(4), $373-382$. https://doi.org/10.1093/elt/ccv030

Lin, M. H. (2015). Learner-centered blogging: A preliminary investigation of EFL student writers' experience. Educational Technology \& Society, 18(4), 446-458.

Lin, M. H. (2016). Effects of corpus-aided language learning in the EFL grammar classroom: A case study of students' learning attitudes and teachers' perceptions in Taiwan. TESOL Quarterly, 50(4), 871-893. https://doi.org/10.1002/tesq.250

Lin, M. H. (In press). Language blogging community: Fostering the learning attitudes and writing skills of EFL students. International Journal of English Linguistics, 9(3). https://doi.org/10.5539/ijel.v9n3p1

Lin, Y. Y. (2007). An exploratory study of English multimedia writing: implementing Weblogs in a college composition class. Unpublished Master's dissertation, National Tsing Hua University, Taiwan.

McNeill, B. R. (2006). A comparative statistical assessment of different types of EFL writing by Japanese college students. Unpublished PhD dissertation. University of Birmingham, Birmingham, UK.

Ooi, V. B. Y. (2001). Investigating and teaching genres using the World Wide Web. In M. Ghadessy, A. Henry \& R. L. Roseberry (Eds.), Small Corpus Studies and ELT: Theory and Practice (pp. 175- 203). Amsterdam: John Benjamins. https://doi.org/10.1075/scl.5.12ooi

Ooi, V. B. Y., Tan, P. K. W., \& Chiang, A. K. L. (2007). Analyzing personal weblogs in Singapore English: the Wmatrix approach. In eVariEng (Journal of the Research Unit for Variation, Contacts, and Change in 
English), 2 (Towards Multimedia in Corpus Studies). Finland: University of Helsinki.

Pinkman, K. (2005). Using blogs in the foreign language classroom: Encouraging learner independence. The JALT CALL Journal, 1, 12-24.

Reinhardt, J. (2019). Social media in second and foreign language teaching and learning: Blogs, wikis, and social networking. Language Teaching, 52(1), 1-39. https://doi.org/10.1017/S0261444818000356

Robertson, D. (2000). Variability in the use of the English article system by Chinese learners of English. Second Language Research, 16, 135-172. https://doi.org/10.1191/026765800672262975

Roed, J. (2003). Language learner behaviour in a virtual environment. Computer Assisted Language Learning, 16, 155-172. https://doi.org/10.1076/call.16.2.155.15880

Scott, M., \& Tribble, C. (2006). Textual patterns: Key words and corpus analysis in language education. Amsterdam: John Benjamins Publishing Co. https://doi.org/10.1075/scl.22

Shepherd, M., \& Watters, C. (2004). Identifying web genre: Hitting a moving target. In Proceedings of the WWW2004 Conference: Workshop on Measuring Web Search Effectiveness: The User Perspective. New York.

Snape, N., Mayo, del P. G., \& Gürel, A. (2009). Spanish, Turkish, Japanese and Chinese L2 Learners' Acquisition of Generic Reference (pp. 1-8). In Proceedings of the 10th Generative Approaches to Second Language Acquisition Conference (GASLA 2009). Somerville, MA: Cascadilla Proceedings Project.

Sun, Y. C. (2010). Extensive writing in foreign-language classrooms: a blogging approach. Innovations in Education and Teaching International, 47(3), 327-339. https://doi.org/10.1080/14703297.2010.498184

Thornbury, S. (2004a). Big words, small grammar. English Teaching Professional, 31, 10-11.

Thornbury, S. (2004b). Natural grammar: the keywords of English and how they work. Oxford: Oxford University Press.

Tuan, L. T. (2010). Enhancing EFL learners' writing skill via journal writing. English Language Teaching, 3(3). https://doi.org/10.5539/elt.v3n3p81

Warschauer, M., \& Grimes, D. (2007). Audience, authorship, and artifact: The emergent semiotics of Web 2.0. Annual Review of Applied Linguistics, 27, 1-23. https://doi.org/10.1017/S0267190508070013

Wong, K. M., \& Moorhouse, B. L. (2018). Writing for an audience: Inciting creativity among young English language bloggers through scaffolded comments. TESOL Journal, 9(4), 1-6. https://doi.org/10.1002/tesj.389

Willis, D. (1990). The lexical syllabus: a new approach to language teaching. London: Collins COBUILD.

Xie, Y., Ke, F., \& Sharma, P. (2008). The effect of peer feedback for blogging on college students' reflective learning processes. Internet and Higher Education, 11, 18-25. https://doi.org/10.1016/j.iheduc.2007.11.001

\section{Copyrights}

Copyright for this article is retained by the author, with first publication rights granted to the journal.

This is an open-access article distributed under the terms and conditions of the Creative Commons Attribution license (http://creativecommons.org/licenses/by/4.0/). 